\title{
The Impact of Intonational Changes on Male and Female Teenagers' Inferencing and Listening Comprehension
}

\author{
Leila Barati $^{1}$, Morteza Bakhtiarvand ${ }^{2}$ \\ ${ }^{1}$ Islamic Azad University, Khorasgan, Department of Linguistics, Isfahan, Iran \\ ${ }^{2}$ Allameh Tabatabai University, Department of Educational Science and Psychology, Tehran, Iran \\ Email address: \\ Leilabarati6093@yahoo.com (L. Barati),m_bakhtiarvand@yahoo.com (M. Bakhtiarvand)
}

\section{To cite this article:}

Leila Barati \& Morteza Bakhtiarvand. The Impact of Intonational Changes on Male and Female Teenagers' Inferencing and Listening Comprehension. International Journal of Language and Linguistics. Vol. 3, No. 6, 2015, pp. 367-371. doi: 10.11648/j.ij11.20150306.18

\begin{abstract}
According to Buck (2003), in the listening comprehension the input in the form of sounds and intonational clues often conveys additional information. This paper considers the impact of intotational (falling and rising) changes on children language acquisition and children's linguistic experiences as an important factor that assists in the emerging social and emotional development of the children's inferencing. During the study two fiction and non-fiction passages were read to participants in experimental and control groups respectively and accordingly participants have different comprehension ability.
\end{abstract}

Keywords: Intonation, Inferencing, Infants, Competence, Context

\section{Introduction}

Since language development is clearly shaped by linguistic experiences the importance of language input cannot be doubted. Even at the one-word stage of language acquisition, young children are beginning to adhere to the adult tendency to coordinate nonverbal and verbal behaviors, and that intentional meaning is more comprehensible when gesture and intonation contour are coordinated.

Developmental studies of the early utterances of children and phonetic studies of related and unrelated languages show that intonational signal has a linguistic reference in the first years of life. The influence of language input on language acquisition is also evident in experiments with pre-lingual infants between six and nine months. Jusczyk (1993), shows that these infants exhibit a preference for the specific characteristics of their native language, such as the phonemic repertoire, prosodic regularities, and phonotactic constraints.

In short, linguistic experience shapes speech perception. Children usually use the words that store in their personal lexicon. Each lexical item is sets of entailment and presupposed schemata which determine the logical consequences triggered by that item when it appears in an utterance. Moreover, it has been shown that infants prefer to listen to speech in this Speech style (e.g., speech with intonation change) rather than to normal speech, (Flavell, 1992).
Pragmatically listeners interpret the intonational signals in terms of features through a process of analysis that called inference. Inference is the relationship between speaker and utterance, and listener's comprehension from his point of view. As intonation and other supra-segmental features are parts of utterance, listener according to situational presupposition with speaker can do interpretation.

According to this fact that intonational aspects in mother tongues differ from language to language and also from child to child, this study tries to consider the influence of these factors on listening comprehension and inferencing skil (Duck \& Bennet, 2003).

\section{Intonationn Aspects in Speech}

The term supra-segmental refers to variations in pitch, timing, and amplitude of utterances. These variations can be determined by linguistic factors such as focal emphasis, syntactic structure or by nonlinguistic factors such as different speech styles, different speakers and different emotions (Laing $\&$ kamhell, 2002). In this regard the variables that measure are pitch, intonation, and speech rate. These intonational aspects also are seen in infants' crying. Children actually produce, perceive and use some aspects of previous or primary intonation in their mother tongue. Intonation refers to distinctive patterns of vocal melody (Liu, 2007).

Indeed, when infants begin to produce speech, they seem to command for the first time a true communication system that 
is complete. This system brings together pragmatic and affective communication skills, which begin to develop in the first months of life. Acoustic analyses of the speech signals and vocal folds should be used in phonetic laboratory and this study ignores this part at all. In the last times of the pregnancy, human fetuses become active listeners. The sense of hearing is the first sensory system that develops. The mother's voice, in particular, is sensed early on.

According to the result of a study by researchers from the Max Planck Institute (ZVES, 2009) at the University Clinic Würzburg, and the Laboratory of Cognitive Sciences and Linguistics at the Ecole Normale Supérieure in Paris, in the first days of their lives, infants already cry in a different way from each other. The infant cry has a characteristic pattern that is innately determined. These patterns have a rising-falling frequency contour (Myhill, Jones, \& Hopper, 2006). The speed and time of sound acquisition varies enormously between different children but the sequence and the relative chronology are always and everywhere the same (Mills, 2005). The intonation patterns of the respective mother tongue are already ingrained in the brains of four-month-old babies. The analysis of infants' crying showed that the newborns tended to produce the intonation pattern most typical for their respective mother tongue.

Levinson (2000), believes that intonation as a syntactic device is one of the first speech signals that has a linguistic reference. Naturally, children soon mimic adult intonation. The mimicry in speech represents a social use of speech. Levinson (2000, P: 58) speaks about three stages in the development of language: "1-The child's discrimination in a broad way between patterns of expression in intonation. 2-when the phonetic form with intonational form is made effective, at first the intonational form dominates the child's response. 3-The intonationnal patterns may be considered subordinated". Experimental studies have shown that rising pitch is more effortful to produce than falling pitch for most adult speakers. Accordingly, falling also predominates in the speech of preschool children. Falling intonation is controlled by physiology in the earliest stage but later the falling tone comes under linguistic control, (Koisawalia, 2005).

During the very first minutes of life children employ meaningful intonational signals by means of their cries. The infant's cry has a rising - falling fundamental frequency contour. The fundamental frequency initially rises then remains steady and falls until the end of the cry (Walters, 2004). Accordingly, infants from the age of two months responded positively to the human voice while infants from the age of three months responded positively to friendly tones and negatively to angry tones of voices Terken (2000).

\section{Imitation and Inferencing in Children}

Infants' imitative behavior is sophisticated. Children soon mimic adult intonation. The mimicry in speech represents a social use of speech. Perceptual phonetic studies indicate that the intonation pattern associated with normal declarative sentences is characterized by a falling intonation contour at the end of the sentence of a language. Physiological and conceptual experiments indicate that intonation is both produced and perceived in terms of intonational features.

Children faithfully imitate arbitrary actions, because they have few prior expectation about them. On the other hand, children sometimes are override imitate actions and use their own meanness or ways to end action. Children assume that the adults' information is reliable and worth learning. However, children respond differentially to probabilistic and deterministic evidence in a wide range of context. Imitation paradigms can help us understand how children represent the causal structure of events (Cambell \& Backman, 1999).

Emotion understanding is one of the most important constituents of social understanding in pragmatic. It deals with comprehension of the nature, causes, consequences and possibilities of control and regulation of emotions. These various aspects of emotion understanding develop with age. Understanding of external features of emotion emerges at around 4-5 years, of various mental aspects of emotion (impact of desires and beliefs, distinction between real and apparent emotions) appears at around 6-7 years and of cognitive reflection (mixed and moral emotions, mental control of emotion) emerges at around 8-9 years.

Accordingly, pragmatics seems to come out as one of the most important factors in children's emotion understanding (Harris, 2000). As children grow and start experiencing new situations they actively try to decipher events in their environment by inferring similarities and differences of each new event (Hansen \& Pearson, 1983).

Lathman, (2008), examined the role of cultural schemata on the children comprehension and concluded that cultural schemata influence the processing strategies as well as the level of comprehension.

\section{The Impact of Intonation on Inferencing}

Hearer uses inference to recognize the communicative intention of the speaker and given the recognition of that intention and the particular form of the ostensive act, the addressee can infer the intended information. According to Keene and Zimmerman (1997), inferring is going beyond the literal text, making it personal and three-dimensional, and weaving it into our own stories. Language is not the basis of communication, but simply an instrument used to help the interpreter more easily infer the speaker's communicative intention, as it constrains that inferential process by reducing the number of assumptions that could potentially be part of the context of interpretation ( Kennision\& Gordon, 2002).

As pointed, variation in overall discourse structure has been found to be conveyed by intonational variation and the role of intonation in conveying affect, or emotional state is important. When listener listens to people's utterance, some sounds or group of sounds in speech can relatively be heard higher or lower than others. This relative height of speech sounds as perceived by a listener is called pitch. The relationship 
between accent and part of speech is also dependent upon context (Terken 2000). Pitch is a perceptual attribute of sound. The physical correlate of pitch is the F0 of vibration in vocal folds. This property is used in speaker's verification, by comparing F0 contours. There are two allophones for this pitch accent: Low-Higher $\left(\mathrm{L}+\mathrm{H}^{*}\right)$ and High $\left(\mathrm{H}^{*}\right)$, the former is used for words and phrases with final stress, e.g., nouns and adjectives longer than one syllable, and also for vocatives. (Adami, 2003).

At some level the brain probably does process phonological patterns differently from semantic or syntactic ones, and there is likely to be some difference between the processing of brain in different sounds that are ultimately treated alike and two that are ultimately distinguished. According to Prat, Keller and Just (2007), individual differences in listening comprehension are associated with brain resources during task performance. Listening comprehension resulted in more overall activation over the whole brain.

\section{Methods and Procedures}

This paper tries to investigate the impact of intonational changes of mother tongue language on children inferencing and comprehension ability. Participants of the present study are 60 persian male and 60 Persian female students who were learning English as a second language in a teaching language center in Shahrekord, Iran. The age range for the participants were $8-13$. The samples were randomly chosen from 100 male and female students Language Center. The students who after Oxford Placement Test (OPT), toke scores between 15 to 18 participate in this study.

The materials for testing participants' inferencing and evaluating their listening comprehension ability of making schematic references consisted of two fiction and two non-fiction passages that were read aloud to participants. Passages were created according to Leslie Holzhauser-Peters, M.S., CCC-SLP, and author. Two fiction and two non-fiction passages were created for each grade level. The passages were no more than 150 words. Each passage was submitted to The Lexile's (2008) Framework for Reading and Listening which matches the appropriate grade level to each text. Each text was given a lexile score, which indicated what grade level, corresponded with each passage.

Participants meet with the researcher during four sessions and every session approximately twenty to thirty minutes. During this session, two fiction and two non-fiction passages are read aloud to participants. Each passage had seven predetermined stopping points where the examiner would stop reading and ask the participant specific questions about the passage and during reading passages researcher asked students some question about passage to detect the participant's inferencing pattern. Participants were given scores based on their intonational clue selection in inferencing and logical thinking skills.

In fiction, a reader has to identify the characters and follow the events of the story because mental states are central in narrative texts. Besides, they present linguistic forms, grammar, phrases, vocabulary, and formulaic speech within a meaningful and structured context that supports comprehension of the narrative world (Glazer \& Burke, 1994; Jennings, 1991; Koisawalia, 2005; Mallan, 1991). According to some studies, non-fiction has a different framework. In non-fiction, a reader or listener needs to comprehend the topic, learn new facts related to it, and be able to find and remember important information (Scharer, Pinnell, Lyons, \& Fountas, 2005).

\section{Data Analysis}

After scoring, the result were put under a series of statistical analyses selected from SPSS software package. Generally, collected data had been analyzed and tabulated as following. In general tables show the relationship between scores of mean and contextual clue selection in two age groups of the present study.

Table 1. Listening comprehension ability and Inferencing Testing of Control Group.

\begin{tabular}{llllll}
\hline & N & Minimum & Maximum & Mean & $\begin{array}{l}\text { Std. } \\
\text { Deviation }\end{array}$ \\
\hline Fiction & 30 & .00 & 4.00 & 2.7667 & .89763 \\
Non-Fiction & 30 & .00 & 4.00 & 2.6600 & 1.02217 \\
$\begin{array}{l}\text { Valid N } \\
\text { (listwise) }\end{array}$ & 30 & & & & \\
\hline
\end{tabular}

Table 2. Listening comprehension ability and Inferencing Testing of Experimental Group.

\begin{tabular}{llllll}
\hline & N & Minimum & Maximum & Mean & Std.Deviation \\
\hline Fiction & 30 & 2.00 & 4.00 & 3.3667 & .57135 \\
Non-Fiction & 30 & 2.00 & 4.00 & 3.0333 & .71840 \\
$\begin{array}{l}\text { Valid N } \\
\text { (listwise) }\end{array}$ & 30 & & & & \\
\hline
\end{tabular}

Tables display that the greatest mean score of fiction passages $(\mathrm{M}=3.36)$ belonged to the comprehension and inferencing in the experimental group and the lowest mean score (2.66) belonged to the comprehension and inferencing of non-fiction in the control group. Following table generally shows the impact of gender, age and intonation on participants inferencing and listening comprehension ability:

Table 3. The impact of gender, age and intonation on Participants' inferencing and listening comprehension ability.

\begin{tabular}{llllll}
\hline Source & $\begin{array}{l}\text { Type III Sum of } \\
\text { Squares }\end{array}$ & df & $\begin{array}{l}\text { Mean } \\
\text { Square }\end{array}$ & F & Sig. \\
\hline Intercept & 2220.417 & 1 & 2220.417 & 4005.728 & .000 \\
Gender & .017 & 1 & .017 & .030 & .005 \\
Age & 4.267 & 1 & 4.267 & 7.697 & .006 \\
Intonation & 15.000 & 1 & 15.000 & 27.061 & .000 \\
Error & 64.300 & 116 & .554 & & \\
\hline
\end{tabular}

As Table 3 demonstrates, gender as a variable had meaningful impact on the listening comprehension ability. Significant level of this variable on the listening comprehension $(0.005)$ was less than 0.05 . It means that there is some significant difference between male and females' inferencing and listening comprehension ability.

Also according to this Table 3, significant levels of both 
variables age (0.006) and intonation (0.000) on the listening comprehension ability were less than 0.05 . In the other words age and intonation had meaningful impact on the participants' inferencing and listening comprehension ability, too.

\section{Results and Discussion}

According to findings of this study, the investigations are in agreement with some previous researches pointing to the importance of listening comprehension ability on the development of inferencing ability. Duke (2000) defined informational context as what had a function to communicate information about the natural or social world.

According to Hassan (2000) listener selects information from the auditory cues according to personal knowledge. Therefore, in listening comprehension process, the phonological information are the first things that listener receives from speaker's speech and matches them with his mental information and identifies, interprets and comprehends meaning of the words or phrases he listened to. Listener as the first step of listening comprehension identifies sound signals according to speaker's utterances and selects intonational clues of the overall context.

Thus, when speaker does not apply intonational counters in the utterance and speaker's prosodic knowledge is inadequate inferencing will not be made correctly and comprehension will be weak or incorrect. On the other hand, when listener is not familiar with the prosodic system and contextual features of the language the attention-focusing mechanism will not be employed and as a result comprehension cannot correctly be made. The significant gains of the experimental group in this study stated that considering intonational clues in the speakers' utterance had positive impact on listeners' inferencing and comprehension. For the experimental group, the pitch of the voice raised and lowered to form pitch patterns as intonnational clues of utterance. Each intonation clue as a prosodic characteristic in speech reveals some important information regarding the identity of the spoken language.

This study, based on obtained statistic results of Tables concludes that age, gender and intonatinal differences influenced participants' inferencing and comprehension ability. Besides, when the influence of intonational changes in this study were considered for male and females in this age group, the results showed that, accordingly, older participants had the most lexile's listening comprehension scores than younger. Also according to the statistical results of the study males' inferencing and comprehending of the non-fiction passages were more than females.

Previous research have supported the theory that inferencing abilities are linked to prior knowledge, reading levels and comprehension, along with grade level, clue selection, and logical thinking abilities (Beers, 2002; Crais \& Chapman, 1987; McCormick \& Hill, 2001; Leslie \& Caldwell, 2009; wagner, 2006; Vandergrift, 2004). Future research can focus on presenting the same procedures to larger population to determine if any developmental changes occur within the groups which are clue selection, logical thinking, reading level, and overall inferential thinking abilities. Future researches can also specifically investigate fiction versus non-fiction passages in relation to the development of emotional abilities.

\section{References}

[1] Adams, B. C. Bell, L. C., \& Perfetti, C. A. (2004). A trading relationship between reading skill and domain knowledge in children "s text comprehension. Discourse Processes, 20,307-323.

[2] Anderson, K, \& Lynch, T. (2003). Learner/non-teacher interactions: the contribution of a course assistant to EAP speaking classes. Interaction and Language Learning. TESOL Case Studies in Practice series. Alexandria, VA: TESOL. 7-22.

[3] Anderson, R., \& Pearson, P. (1984). A schema-theoretic view of reading comprehension. In P. D. Pearson (Ed.), Handbook of Reading Research (pp. 255-291). New York: Longman.

[4] Auer, P. \& Luzio, A. D. (2009). The Contextualization of Language. A Methodological Paradigm Discussion. Oxford University Press.

[5] Brentari, D. (2008).The relationship between early gestures and intonation. Purdue University of SAGEpublication.

[6] Beers, K. (2002). When kids can "s read: What teachers can do. Portsmouth, NH: Heinemann.

[7] Bowyer-Crane, C., \& Snowling, M. J. (2005). Assessing children's inference generation: What do tests of reading comprehension measure? British Journal of Educational Psychology, 75, 189-201.

[8] Carrow-Woolfolk, E. (1999). Comprehensive assessment of spoken language. Circle Pines, MD. American Guidance Service, Inc.

[9] Csibra, G, \& Gergely, G. (1998).The teleological origins of mentalistic action explanations: A developmental hypothesis.Developmental Science, 1,255-259.

[10] Duke, N., \& Bennett-Armistead, V. (2003). Reading and writing informational text in the primary grades: Research-based practices. New York: Scholastic.

[11] Flavell, H. (1992). An analysis of cognitive-developmental sequences. A theory-of-mind development. Stanford University, California 94305-2130.

[12] Gumperz, J. (2001). Contextualization and understanding. Rethinking context, ed. By Alessandro Duranti and Charles Goodwin, 229-252. Cambridge: Cambridge University Press.

[13] Greenacre, M. J. (1984). Theory and applications of correspondence analysis. London: Academic Press.

[14] Hansen, J. (2000). Inferential comprehension strategy for use with primary grade children. The Reading Teacher, 34, 665-669.

[15] Horner, V. \& Whiten, A. (2005).Causal knowledge and imitation/emulation switching in chimpanzees and children. Animal cognition, 8(3),164-181.

[16] Harris, P. L. (2000). Understanding emotion. In M. Lewis \& J. Haviland-Jones (Eds.), Handbook of emotions (2nd ed.) (pp. 281-292). New York: Guilford Press. 
[17] Huckin, T., \& Bloch, J. (1993). Strategies for inferring word-meanings in context: A cognitive model. In T. Huckin, M. Haynes \& J. Coady (Eds.) Second Language Reading and Vocabulary Learning (pp. 153-178).

[18] Ido, D. \& Oren, G. (2004). Probabilistic tex-tual entailment: Generic applied modeling of language variablity. In Learning Methods for Text Understand-ing and Mining, Grenoble, January.

[19] Glazer, S., \& Burke, M. (1994). An integrated approach to early literacy. Australian Review of Applied Linguistics 15 (1), pp. 95-106.

[20] Jusczyk, P. (1993). Infants' preference for the predominant stress pattern of English words. Child Developments 64,657-686

[21] Kennision, S. M., \& Gordon, P.C. (2002). Comprehending referential expressions during reading and listening: Evidence from eye tracking. Discourse processes, 24,229-252.

[22] Koisawalia, H. (2005). Reading or listening to a story offers a joyful experience in Inferencing. Applied Linguistics 13 (3), pp. 239-258.

[23] Laing, S. P., \& Kamhi, A. G. (2002). The use of think-aloud protocols to compare inferencing abilities in average and below-average readers. Journal of Learning Disabilities, 35, 436-437.

[24] Latham, R. (2003). Facilitators and inhibitors of the transfer of knowledge. Scientist and practitioners in human resource, New York University Press, 43-8.

[25] Latham, R. (2008). Linguistics and Cultures. School of Languages, Action Learning and Appreciative Enquiry. Manchester University Press.

[26] Leslie, L. \& Caldwell, J. (2009).Social linguistics and literacies: Ideology in discourses, Formal and informal measures of reading. Princeton University, Princeton, NJ 08544, 230-331.

[27] Levinson, S. (2000). Presumptive meanings. Cambridge, MA: MIT Press.

[28] Lieven Feeney, A., Scafton, S., Duckworth, A., \& Handley, S. J. (2004). The storysome: Everyday pragmatic inferences by children and adults. Canadian Journal of Experimental Psychology, 58, 121-132.

[29] Liu, F. (2007). The neutral tone in question intonation in Mandarin. Proceedings of Inter speech (pp. 630-633).
[30] McKoon, G., \& Ratcliff, R. (1992). Inference during reading. Psychological Review, 99 (3), 440-466.

[31] Mils, B. (2005). Culture, Literature \& Linguistics; Karora singh Dhaliwal established was Hoshiarpur and its surrounding areas.

[32] Myhill, D., Jones, S.,\& Hopper, R.(2006). Talking, listening and learning: effective talk in the primary classroom, Open University Press.

[33] Ohio Department of Education (2005). Academic content standards K-12 English language arts. Columbus, $\mathrm{OH}$.

[34] Scharer, P., Pinnell, S., Lyons, C., \& Fountas, I. (2005). Becoming an engaged reader. Educational Leadership, 63(2), 24-29. Retrieved from http://www.ascd.org/portal/site/ascd/menuitem.a4db.

[35] Sperber, D. (1995). Relevance, communication and cognition, 2nd Edition. Oxford: Blackwell.

[36] Terken, D. (2000). Emotion understanding in children. From an International Journal of BehavioralDevelopment, 28(5), 471-478.

[37] Tomasello, M. (1998). The new psychology of language: Cognitive and functional approaches to language structure. Mahwah, NJ: Erlbaum.

[38] Vandergrift, L. (2004). Listening to learn or learning to listen. Annual Review of Applied Linguistics 24: 3-25. 320.

[39] Wagner, D. T. (2006). How knowledge helps. [Online] Available:

http://www.aft.org/pubs-reports/american_educator/issues/spri ng06/willingham.htm

[40] Wilson, M. M. (1979). The processing strategies of average and below average readers answering factual and inferential questions on three equivalent passages. Journal of Reading Behavior, 11, 235-245.

[41] Walters, J. R. (2004). Applications of Discourse Intonation II: August www.speechinaction.

[42] Zwaan, R. A., \& Brown, C. M. (1996). The influence of language and proficiency and comprehension skills on situation-model construction. Discourse Processes, 21, 289-327. 